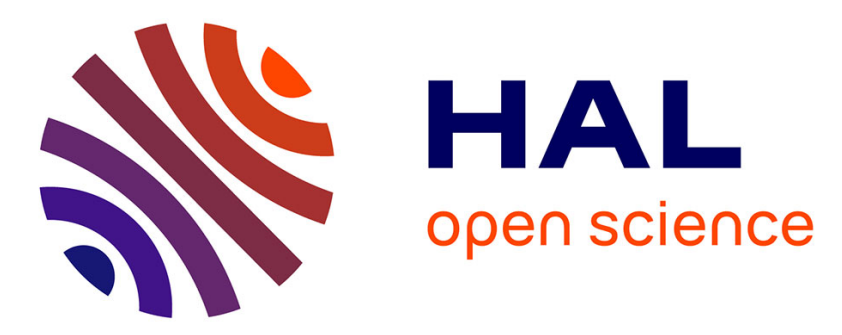

\title{
An experimental investigation of thermal effects in a cavitating inducer
}

Jean-Pierre Franc, Claude Rebattet, A. Coulon

\section{To cite this version:}

Jean-Pierre Franc, Claude Rebattet, A. Coulon. An experimental investigation of thermal effects in a cavitating inducer. 5th International Symposium on Cavitation (CAV 2003)., Nov 2003, Osaka, Japan. hal-00216162

\section{HAL Id: hal-00216162 \\ https://hal.science/hal-00216162}

Submitted on 26 Apr 2020

HAL is a multi-disciplinary open access archive for the deposit and dissemination of scientific research documents, whether they are published or not. The documents may come from teaching and research institutions in France or abroad, or from public or private research centers.
L'archive ouverte pluridisciplinaire HAL, est destinée au dépôt et à la diffusion de documents scientifiques de niveau recherche, publiés ou non, émanant des établissements d'enseignement et de recherche français ou étrangers, des laboratoires publics ou privés. 


\section{AN EXPERIMENTAL INVESTIGATION OF THERMAL EFFECTS IN A CAVITATING INDUCER}

\author{
Jean-Pierre FRANC \\ LEGI, Grenoble, France \\ Jean-Pierre.Franc@hmg.inpg.fr
}

\author{
Claude REBATTET \\ CREMHYG, Grenoble, France \\ Claude.Rebattet@hmg.inpg.fr
}

\author{
Alain COULON \\ SNECMA, Vernon, France \\ alain.coulon@snecma.fr
}

\begin{abstract}
The thermal effects which affect the development of leading edge cavitation in an inducer were investigated experimentally using refrigerant R114. For different operating conditions, the evolution of the cavity length with the cavitation parameter was determined from visualizations. The tests were conducted up to two-phase breeding. The comparison of tests in R114 and in cold water allowed us to estimate the amplitude of the thermodynamic effect. The results show that the B-factor depends primarily upon the degree of development of cavitation but not significantly upon other parameters such as the inducer rotation speed or the fluid temperature, at least in the present domain of investigation. These trends are qualitatively in agreement with the classical entrainment theory. In addition, pressure fluctuations spectra were determined in order to detect the onset of cavitation instabilities and particularly of alternate blade cavitation and rotating cavitation. If the onset of alternate blade cavitation appeared to be connected to a critical cavity length, the results are not so clear concerning the onset of rotating cavitation.
\end{abstract}

\section{NOMENCLATURE}

a thermal diffusivity or eddy diffusivity

B B-factor of Stepanoff (eq.2)

$\mathrm{C}_{\mathrm{p}}$ pressure coefficient

$\mathrm{c}_{\mathrm{p} \ell} \quad$ liquid heat capacity

$\mathrm{D}$ characteristic diameter of the inducer

e cavity thickness

$\ell \quad$ cavity length

$\mathrm{h}$ convection heat transfer coefficient

$\mathrm{L} \quad$ latent heat of vaporization

$\mathrm{Nu}_{\ell} \quad$ Nusselt number based on cavity length

$\mathrm{p} \quad$ pressure

$\mathrm{p}_{\mathrm{c}} \quad$ cavity pressure

$\mathrm{p}_{\text {ref }}$ reference pressure

$\mathrm{p}_{\mathrm{v}} \quad$ vapor pressure

Pr Prandtl number

q heat flux

$\mathrm{R}$ bubble radius

$\dot{\mathrm{R}} \quad$ bubble wall velocity

$\operatorname{Re}_{\ell} \quad$ Reynolds number based on cavity length

t time

$\mathrm{T}$ temperature

$\mathrm{T}_{\mathrm{c}} \quad$ temperature of cavity
$\mathrm{T}_{\infty} \quad$ liquid temperature at infinity

$\mathrm{V}$ flow velocity

$\dot{v}_{\ell} \quad$ volume flow rate of liquid

$\dot{\mathcal{V}}_{\mathrm{v}} \quad$ volume flow rate of vapor

$\mathrm{x}$ distance

$\alpha \quad$ void fraction

$\delta \quad$ thermal boundary layer thickness

$\Delta \mathrm{T}$ thermodynamic effect

$\Delta \mathrm{T} *$ characteristic temperature difference (eq.1)

$\lambda$ thermal conductivity

$\rho_{\mathrm{v}} \quad$ vapor density

$\rho_{\ell} \quad$ liquid density

$\sigma \quad$ cavitation number (eq.13)

$\sigma_{\mathrm{c}} \quad$ cavitation number based on cavity pressure (eq.14)

$\Sigma \quad$ thermodynamic parameter (eq.30)

\section{INTRODUCTION}

When cavitation occurs in a liquid flow, part of the liquid changes into vapor in the low pressure regions. The latent heat of vaporization involved in the phase change makes that the twophase medium is somewhat colder than the oncoming liquid. The temperature difference $\Delta \mathrm{T}$ between the liquid at infinity and the cavitating region is usually made non-dimensional using the characteristic temperature difference:

$$
\Delta \mathrm{T}^{*}=\frac{\rho_{\mathrm{v}} \mathrm{L}}{\rho_{\ell} \mathrm{c}_{\mathrm{p} \ell}}
$$

This reference quantity depends only upon the nature of the fluid. The non-dimensional temperature difference:

$$
\mathrm{B}=\frac{\Delta \mathrm{T}}{\Delta \mathrm{T} *}
$$

is the classical B-factor of Stepanoff [1-2]. Assuming that, a volume $\dot{V}_{\mathrm{v}}$ of vapor is formed per unit time and that the latent heat of vaporization is taken from a volume $\dot{v}_{\ell}$ of liquid, the heat balance gives:

$$
\mathrm{B}=\frac{\dot{v}_{\mathrm{v}}}{\dot{\mathrm{V}}_{\ell}}
$$

If the cavitating region is considered as a two-phase mixture of void fraction $\alpha$ and typical thickness e, and assuming, in a basically dimensional approach, that the two-phase mixture is entrained with the general flow velocity V (Figure 1), we have per unit span length: 


$$
\begin{gathered}
\dot{\mathcal{V}}_{\mathrm{v}} \approx \alpha \mathrm{eV} \\
\dot{\mathcal{V}}_{\ell} \approx(1-\alpha) \mathrm{eV} \\
\mathrm{B} \approx \frac{\alpha}{1-\alpha}
\end{gathered}
$$

This very simple approach shows that the B-factor is of order unity unless the cavity is full of vapor $(\alpha=1)$. In other words, the characteristic temperature difference $\Delta \mathrm{T}^{*}$ can usually be considered as a reasonable estimate of the actual temperature difference $\Delta \mathrm{T}$.



Figure 1: Typical two-phase cavity

In the case of water at room temperature, $\Delta \mathrm{T}^{*} \cong 0.01 \mathrm{~K}$ whereas $\Delta \mathrm{T}^{*} \cong 1.2 \mathrm{~K}$ for liquid hydrogen at $22.2 \mathrm{~K}$. Thus, if thermal effects can be considered as negligible in water, it is not the case in $\mathrm{LH}_{2}$ used in rocket engines.

For a full vapor cavity, only the surrounding liquid can supply the heat for vaporization since there is no liquid inside the cavity. This situation was analyzed by several investigators as Holl, Billet \& Weir [3], Kato [4], Fruman, Reboud \& Stutz [5]. Still from a dimensional viewpoint, the vapor is assumed to be entrained at a flow velocity of the order of the liquid flow, so that (Figure 2):

$$
\dot{v}_{\mathrm{v}} \approx \mathrm{eV}
$$

The liquid concerned by heat transfer is contained in a thermal boundary layer of thickness $\delta$ which develops on the interface, so that:

$$
\begin{aligned}
& \dot{v}_{\ell} \approx \delta \mathrm{V} \\
& \text { and thus: } \\
& \mathrm{B} \approx \frac{\mathrm{e}}{\delta}
\end{aligned}
$$

As the transit time along the cavity of length $\ell$ is $\ell / \mathrm{V}$, the boundary layer thickness can be estimated by:

$$
\delta \approx \sqrt{\mathrm{a} \frac{\ell}{\mathrm{V}}}
$$

where a is the thermal diffusivity. Kato [4] shows that turbulent mixing may very significantly enhance heat transfer in comparison with pure conduction. The thermal diffusivity to be considered is then an eddy diffusivity. Fruman et al. [6] proposed to estimate it, considering that the liquid flow on the cavity is analogous to that on a rough wall. In the case of a full vapor cavity, the B-factor can therefore be estimated by:

$$
\mathrm{B} \approx \frac{\mathrm{e}}{\sqrt{\mathrm{a} \frac{\ell}{\mathrm{V}}}}
$$

This relation is very similar to that which is found in the case of a single spherical bubble whose radius grows from a negligible value to R (cf. e.g. Brennen [7] or eq.28):

$$
\mathrm{B} \approx \frac{\mathrm{R}}{\sqrt{\mathrm{at}}}
$$

where $\mathrm{t}$ is the growth time.

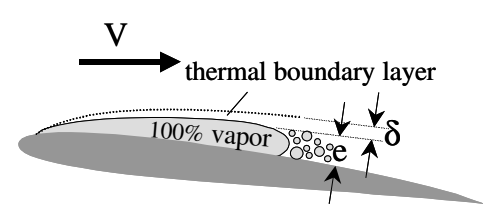

Figure 2: Typical full vapor cavity

In practical applications, a major problem is to estimate the amplitude of the thermodynamic effect i.e. of the B-factor. Several researchers as Hord [8], Billet [9], Fruman, Reboud \& Stutz [5] have measured the temperature depression on ogives, hydrofoils or venturis for different operating conditions and different fluids. These data have been used either to derive semiempirical correlations or to adjust predictive models. As an example, Fruman et al. [6] developed a model based on the entrainment theory which gives a reasonable prediction of the thermodynamic effect for two-dimensional sheet cavitation.

In the case of a rotating machinery as a rocket engine inducer, the direct measurement of the temperature depression on a rotating blade is more difficult. It is the reason why we tried to estimate the B-factor without measuring directly the temperature inside the cavitating region. Preliminary experiments [10] showed that this is possible from visualizations of the extent of the sheet cavity. The principle is elementary and based upon classical scaling rules in terms of the cavitation parameter.

There are two different ways to define the cavitation parameter. It can be calculated from the vapor pressure computed at the liquid temperature at infinity $\mathrm{T}_{\infty}$ :

$$
\sigma=\frac{p_{\text {ref }}-p_{\mathrm{v}}\left(\mathrm{T}_{\infty}\right)}{\frac{1}{2} \rho \mathrm{V}^{2}}
$$

or from the actual cavity pressure $\mathrm{p}_{\mathrm{c}}$ equal to the vapor pressure at the actual temperature of the cavity $\mathrm{T}_{\mathrm{c}}$ :

$$
\sigma_{\mathrm{c}}=\frac{\mathrm{p}_{\mathrm{ref}}-\mathrm{p}_{\mathrm{c}}}{\frac{1}{2} \rho \mathrm{V}^{2}}=\frac{\mathrm{p}_{\mathrm{ref}}-\mathrm{p}_{\mathrm{V}}\left(\mathrm{T}_{\mathrm{c}}\right)}{\frac{1}{2} \rho \mathrm{V}^{2}}
$$

Both cavitation numbers are connected by:

$$
\frac{1}{2} \rho \mathrm{V}^{2}\left(\sigma_{\mathrm{c}}-\sigma\right)=\frac{\mathrm{dp}_{\mathrm{v}}}{\mathrm{dT}} \Delta \mathrm{T}
$$

This relation shows that the thermodynamic effect $\Delta \mathrm{T}$ on the right-hand side can be estimated from the difference in cavitation numbers $\sigma_{\mathrm{c}}-\sigma$. The value $\sigma$ is determined from the general operating conditions, whereas $\sigma_{\mathrm{c}}$ is estimated from reference tests conducted in cold water, i.e. without thermal effects. The method consists in assuming that the cavity length is a function of the only cavitation number $\sigma_{c}$ whatever may be the fluid. This is a classical scaling rule which is further discussed in section 5 . The value $\sigma_{\mathrm{c}}$ can then be obtained from a test in water leading to the same development of cavitation.

\section{EXPERIMENTAL FACILITY}

The fluid used for the tests is the refrigerant $\mathrm{R} 114$ (dichlorotetrafluoroethane $\mathrm{C}_{2} \mathrm{Cl}_{2} \mathrm{~F}_{4}$ ) between $20^{\circ} \mathrm{C}$ and $40^{\circ} \mathrm{C}$. The corresponding vapor pressure varies between $1.8 \mathrm{bar}$ and 3.4 bar. The characteristic temperature difference $\Delta \mathrm{T}^{*}$ increases from about 1.2 to 2.0 in this temperature range. Such values are very comparable to that of liquid hydrogen. Hence, it is expected 
that the thermodynamic effect in $\mathrm{LH} 2$ can be reasonably well approached by tests in R114. However, other parameters are significantly different such as the Prandtl number which is about 1 for LH2 and 5 for R114, so that deviations can also be expected. The problem of the transposition from R114 to LH2 is not addressed in the present work.

The experimental facility includes a resorption tank of $2.6 \mathrm{~m}^{3}$, a pressure control device, a heat exchanger for the control of the fluid temperature, a variable head-loss and the pump to be tested (cf. [10] for a scheme of the facility). The inducer has four blades and its diameter is $182 \mathrm{~mm}$. A flowmeter and several transducers allow the control of the operating conditions: flowrate, rotation speed, pressures and temperatures. The fluid quality is controlled by means of a special degassing device which allows the removal of any non condensable gas dissolved in the liquid before the facility is filled. Figure 3 presents a view of the inlet pipe and the pump.

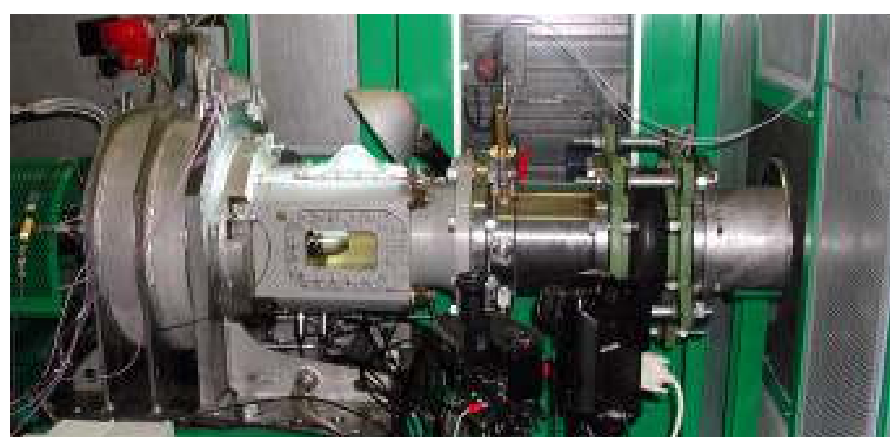

Figure 3: View of the pump together with the inlet pipe. The flow is from right to left. The front window allows the observation of cavitation on the blades.

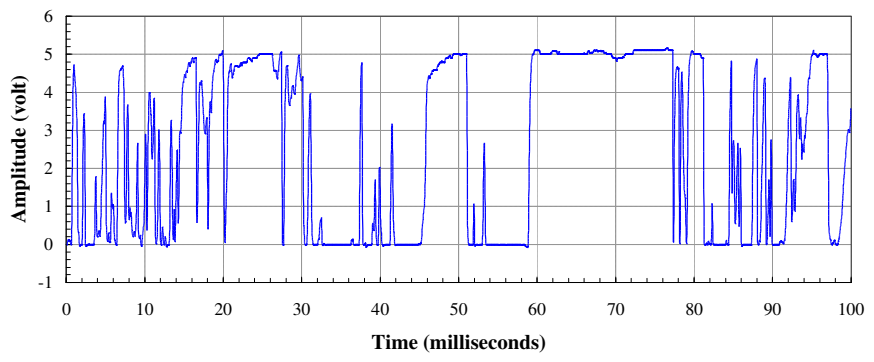

Figure 4: Typical signal given by the optical probe. The lower level ( 0 Volt) corresponds to the liquid whereas the higher level (5 Volt) corresponds to the vapor. The void fraction is estimated from the ratio of the cumulative "vapor time" above a given threshold to the total acquisition time.

The inlet pipe is equipped with an optical probe in order to measure the void fraction in case of two-phase breeding. Figure 4 presents a typical example of the signal given by the probe. Two-phase flow occurs naturally when the inlet pressure reaches the vapor pressure. The core of the flow remains generally liquid whereas the vapor structures develop in a boundary layer whose thickness is of the order of $3 \mathrm{~cm}$. The void fraction was measured at a depth of $1.5 \mathrm{~cm}$ inside the pipe. It has to be noticed that such a local measurement is not representative of the mean void fraction throughout the whole pipe. It is only used here to give a qualitative indication on the quality of the oncoming flow with respect to its two-phase nature. The operation of the inducer in two-phase flow is beyond the scope of the present paper.

This study focuses on sheet cavitation. The cavity length was measured using a grid drawn directly on each blade and visible on Figure 5. It was measured along a unique radius corresponding to the mean radius between hub and casing. At this location, the cavity length is not significantly altered by tipleakage cavitation. The three-dimensional features of the cavity were not investigated. For each operating condition, the cavity length was measured on each of the four blades and the mean value was computed. This procedure allows us to take into account possible differences in cavity lengths from a blade to another which may occur when cavitation instabilities develop. Figure 5 presents typical visualizations of the leading edge cavity during a cavitation test. When the cavitation parameter approaches 0 , two-phase breeding occurs as explained later.

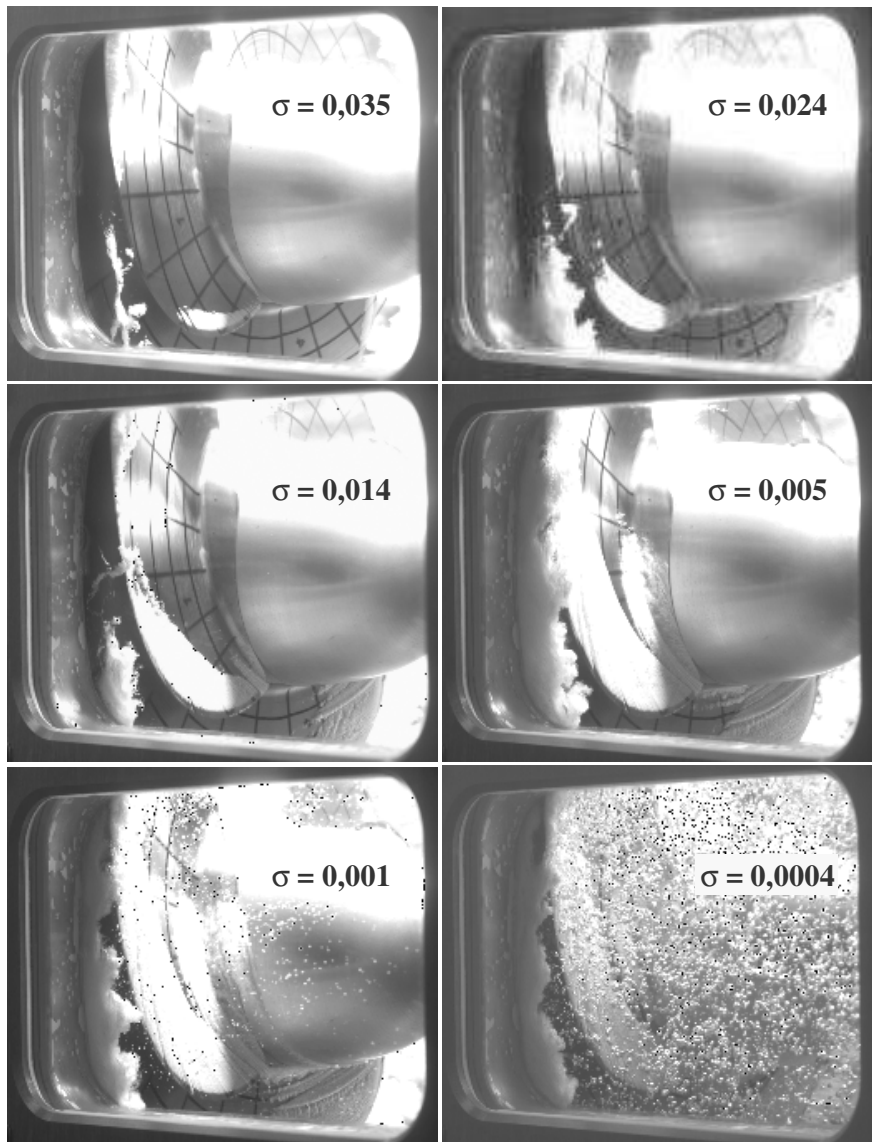

Figure 5: Visualizations of the leading edge cavity for different values of the cavitation parameter up to two-phase breeding. Operating conditions: nominal flowrate, $4000 \mathrm{rpm}, \mathrm{R} 114$ at $20^{\circ} \mathrm{C}$.

Cavitation instabilities were identified from a spectral analysis of pressure fluctuations. Several flush mounted pressure transducers were available at different locations along the casing. The cavitation instabilities are most easily detected from the pressure transducer located close to the leading edge of the blades. Figure $6 \mathrm{~b}$ presents a typical example of the pressure fluctuations spectra. Alternate blade cavitation is easily identified at a frequency twice the rotation frequency. The observation through the windows confirms the alternation of a 
short and a long cavity. This is the first regime of instability observed as the cavitation parameter is decreased. A further decrease leads to the extinction of alternate blade cavitation and the onset of rotating cavitation. The latter is characterized by a frequency slightly greater that the rotation frequency. This frequency is progressively shifted towards the rotation frequency as the cavitation parameter continues to decrease. During rotating cavitation, a relatively short cavity rotates from a blade to the next one, whereas the three other blades have longer cavities. For low values of the cavitation parameter, any cavitation instabilities disappear. Four cavities of equal length develop on each blade and the cavitation regime is balanced.


Figure 6: Typical example of (a) efficiency of the inducer (b) map of pressure fluctuations spectra and (c) cavity length as a function of the cavitation parameter (right-hand side) or indicative void fraction (left-hand side). Operating conditions: nominal flowrate, $4000 \mathrm{rpm}$, $\mathrm{R} 114$ at $20^{\circ} \mathrm{C}$.

The ratio of head to non-cavitating head is given in Figure 6a. It appears that the head does not drop significantly as long as the inlet flow remains purely liquid. The limit of two-phase flow corresponds to $\sigma=0$ since the inlet pressure is here chosen as the reference pressure (see eq.13). For two-phase breeding, the inlet pressure remains equal to the vapor pressure, so that the cavitation parameter remains equal to zero. In order to represent the head loss in two-phase flow, the void fraction is used instead of the cavitation parameter. The corresponding diagram is shown on the left-hand side. Due to the non homogeneous nature of the oncoming two-phase flow, the void fraction considered here is not an estimate of the mean void fraction as already mentioned. However, Figure 6a clearly shows that the head drops mainly because of two phase breeding while the development of the leading edge cavities do not significantly alter the head. This is due to the relatively high thermodynamic effect in R114 which significantly delays the development of leading edge cavities.

A typical evolution of the cavity length with the cavitation parameter is shown on Figure 6c. The cavity length is made non dimensional using the blade spacing, so that a cavity length equal to 1 corresponds to a cavity which extends up to the next blade. The behavior of the graph $\ell(\sigma)$ is quite usual. The RMS value of the cavity length is more important in case of cavitation instabilities, as expected. From the consideration of Figure $6 \mathrm{c}$ and similar graphs $\ell(\sigma)$ obtained for all other operating conditions, it appeared that the present inducer exhibits alternate blade cavitation for a critical cavity length of about $25 \%$. This value has to be compared to the critical value of $65 \%$ that Tsujimoto found from a linear stability analysis of a 2D cascade [12]. On the other hand, the onset of rotating cavitation did not prove to be correlated to a critical cavity length. This point is further discussed in the next section.

\section{THERMODYNAMIC EFFECT}

When the fluid temperature is increased, all other parameters including the cavitation number $\sigma$ being kept constant, the leading edge cavity shrinks as shown on Figure 7. This effect is typical of a thermal delay due to the thermodynamic effect. In order to quantify the phenomenon, the variations of the cavity length with the cavitation parameter were systematically investigated. Figure 8 presents a comparison of the graphs $\ell(\sigma)$ for R114 at two different temperatures. Reference tests in cold water are also indicated. They result of former runs for which the scattering in cavity length was significantly greater than presently. Anyway, the thermodynamic effect is clearly visible since, for a given cavitation number, the cavity is longer in water than in R114 and, moreover, it is longer in $\mathrm{R} 114$ at $20^{\circ} \mathrm{C}$ than at $40^{\circ} \mathrm{C}$.

On the basis of the procedure presented in the introduction (cf. equ.13), the temperature depression was computed for all operating conditions. The fluid temperature was varied between $20^{\circ} \mathrm{C}$ and $40^{\circ} \mathrm{C}$ and the rotation speed between $3000 \mathrm{rpm}$ and $5000 \mathrm{rpm}$. All data were obtained at nominal flowrate. The results are presented in Figure 9. The temperature depression increases with the cavity length. This is a common trend (cf. e.g. [11]) and in the present case, the increase is almost linear. Besides the cavity length, $\Delta \mathrm{T}$ depends primarily upon the fluid temperature but does not depend significantly upon the rotation speed in the range $3000 \mathrm{rpm}$ to $5000 \mathrm{rpm}$. The B-factor defined by eq. (2) was also computed. Results are presented in Figure 10. It is remarkable to observe that all curves tend to collapse in a unique one. In other words, the thermodynamic effect in terms of B-factor is almost independent of the fluid temperature and of 
the rotation speed of the inducer in the present domain of investigation. It depends nearly exclusively upon the degree of development of the cavitation. The dependency is nearly linear with the cavity length.


Figure 7: Effect of the temperature on the development of cavitation at a nearly constant cavitation number $\sigma$. Operating conditions: nominal flowrate, $5000 \mathrm{rpm}, \mathrm{R} 114$.

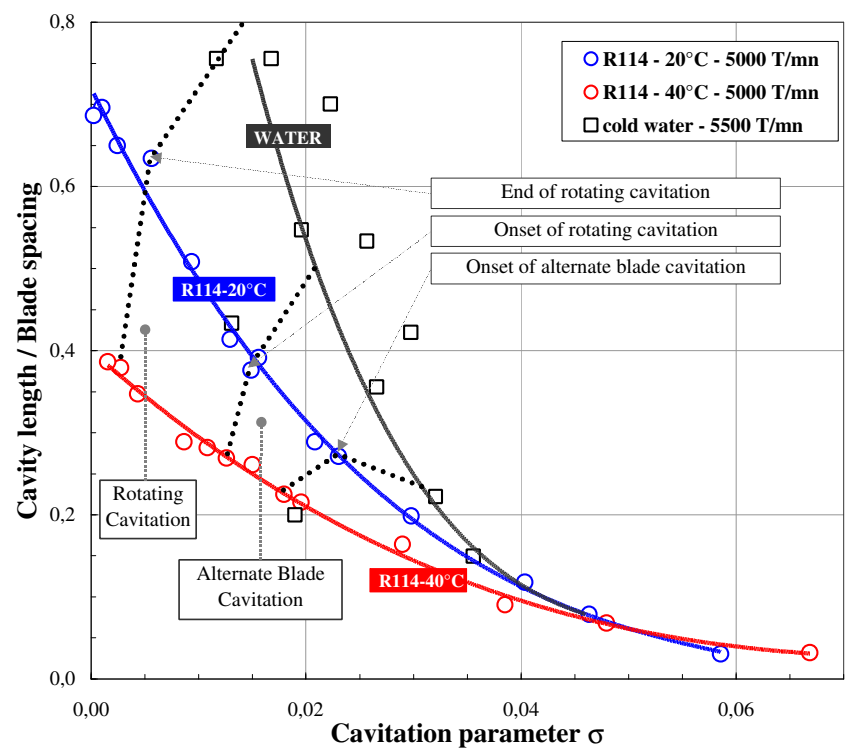

Figure 8: Variation of the cavity length with the cavitation parameter for cold water and for R114 at two different temperatures.

Concerning cavitation instabilities, Figure 8 shows that the onset of alternate blade cavitation has an approximately horizontal limit. This suggests that alternate blade cavitation appears for a critical value of the cavity length of the order of $25 \%$ of blade spacing. This observation holds for all other operating conditions investigated in the present work. Referring to Figure 10, this critical development of cavitation corresponds to a value of the B-factor close to 2 . It can then be concluded that the onset of alternate blade cavitation is affected by a thermodynamic effect whose amplitude is given by a B-factor of the order of 2 . This observation can be used to predict the delay on the occurrence of the first cavitation instabilities due to thermal effects.

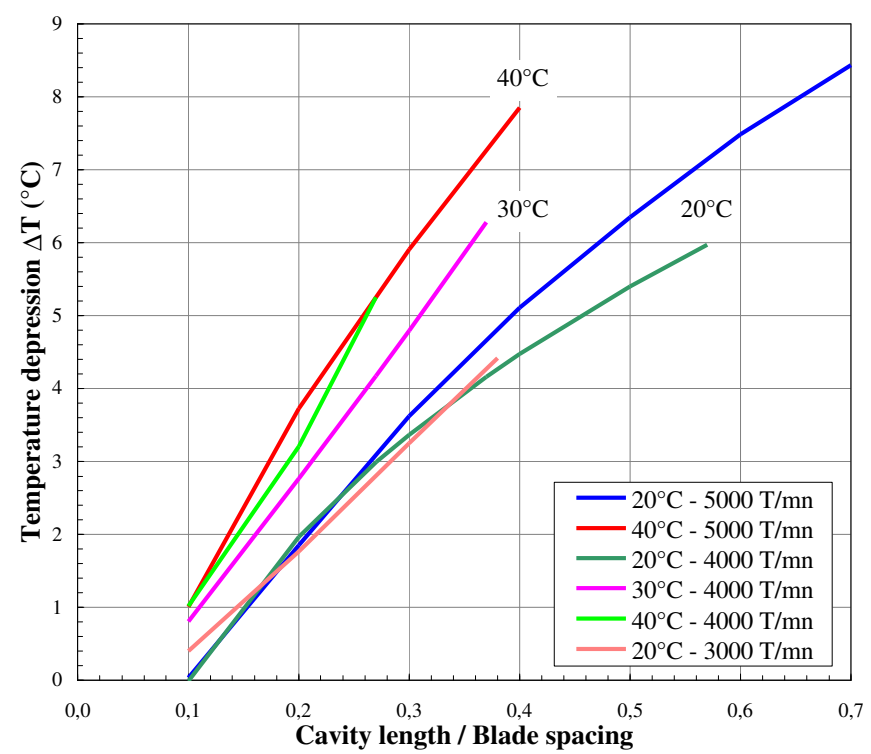

Figure 9: Estimated temperature depression as a function of the cavity length for the inducer working in R114 at different operating conditions and nominal flowrate.



Figure 10: B-factor of Stepanoff as a function of the cavity length for the inducer working in R114 at different operating conditions and nominal flowrate.

As for the transition from alternate blade cavitation to rotating cavitation, the limit in Figure 8 is no longer horizontal. The present results lead then to suppose that the onset of rotating cavitation should not be simply connected to a critical degree of development of the leading edge cavities. Tip-leakage cavitation, whose development is no longer negligible for such regimes, might also contribute to the onset of rotating cavitation together with blade cavitation. It can be conjectured that the key factor is the total volume of vapor inside the inducer and that blade cavitation represents only part of it. 


\section{ANALYSIS OF RESULTS}

The trends observed in the present experimental study are analyzed on the basis of the entrainment theory (Holl et al. [3]). In section 1, the B-factor for a vapor cavity was determined using a conductive type approach. In order to switch to a convective type approach as proposed by Holl et al., we simply identify the expressions of the heat flux given by both theories:

$$
\mathrm{q} \approx \mathrm{h} . \Delta \mathrm{T} \approx \lambda \cdot \frac{\Delta \mathrm{T}}{\delta}
$$

This allows to compute the equivalent boundary layer thickness $\delta$ :

$$
\frac{\delta}{\ell} \approx \frac{\mathrm{h}}{\rho_{\ell} \mathrm{c}_{\mathrm{p} \ell} \mathrm{V}}=\frac{\mathrm{Nu}_{\ell}}{\operatorname{Re}_{\ell} \mathrm{Pr}}
$$

where $\mathrm{Nu}_{\ell}$ and $\operatorname{Re}_{\ell}$ are the Nusselt and Reynolds numbers based on the cavity length $\ell$ and Pr the Prandtl number. Taking into account this expression of $\delta$, equation 9 gives:

$$
\mathrm{B} \approx \frac{\mathrm{e}}{\ell} \frac{\operatorname{Re}_{\ell} \operatorname{Pr}}{\mathrm{Nu}_{\ell}}
$$

Introducing the usual flow rate coefficient of vapor entrained at the rear of the cavity:

$$
\mathrm{C}_{\mathrm{Q} \ell}=\frac{\dot{v}_{v}}{\ell \mathrm{V}} \approx \frac{\mathrm{e}}{\ell}
$$

we finally obtain:

$$
\mathrm{B} \approx \mathrm{C}_{\mathrm{Q} \ell} \frac{\operatorname{Re}_{\ell} \operatorname{Pr}}{\mathrm{Nu}_{\ell}}
$$

This is the classical relation of the entrainment theory as derived by Holl et al. [3]. To estimate the influence of the cavity length on the flow rate coefficient, we refer to experimental data of ventilation obtained by Kamono et al. [13]. Their data were re-plotted in logarithmic scales in order to reveal the exponent of the power law for the evolution of the flow rate coefficient versus the cavity length. From Figure 11, it appears that the flow rate coefficient based on the foil thickness varies approximately as the power 1.5 of the cavity length, so that the flow rate coefficient based on the cavity length as defined by eq. 19 should vary like the square root of the cavity length:

$$
\mathrm{C}_{\mathrm{Q} \ell} \approx \sqrt{\frac{\ell}{\mathrm{c}}}
$$

As for the Nusselt number, we suggest to use, in a first approach, traditional correlations as the one proposed by Dittus and Boetler for convection heat transfer on a wall in fully developed turbulent flow (see i.e. Holman [14]):

$$
\mathrm{Nu}=0.023 \operatorname{Re}^{0.8} \operatorname{Pr}^{0.3}
$$

Fruman et al. [5] showed that heat transfer through the liquid vapor interface can be reasonably well approximated by considering the interface as a solid wall.

By introducing eq. 22 into eq.20, we obtain:

$$
\mathrm{B} \approx \mathrm{C}_{\mathrm{Q} \ell} \operatorname{Re}_{\ell}^{0.2} \operatorname{Pr}^{0.7}
$$

For the present experiments, the Prandtl number varies very little with the fluid temperature, from 5.5 at $20^{\circ} \mathrm{C}$ to 5.0 at $40^{\circ} \mathrm{C}$. It is then impossible to estimate the exponent of the Prandtl number from this work. As for the rotation speed, it appears with exponent 0.2 in eq.23. This small value indicates a small dependency of the B-factor with the rotation speed. From
$3000 \mathrm{rpm}$ to $5000 \mathrm{rpm}$, the term $\mathrm{Re}^{0.2}$ increases of $11 \%$ only. This observation is consistent with the present experimental results which show a small influence of the rotation speed on the B-factor. Eq.23 shows that the major parameter of influence is the cavity length. The above simplified approach suggests that the B-factor varies as the power 0.7 of the cavity length (from eqs.21 and 23). The present work actually demonstrates a major influence of the cavity length on the B-factor. It was observed on Figure 10 that the B-factor is almost proportional to the cavity length. This is not so far from the power 0.7 expected from the entrainment theory. On the whole, the present results appear to be consistent with this theory which shows that the B-factor depends primarily upon the cavity length.

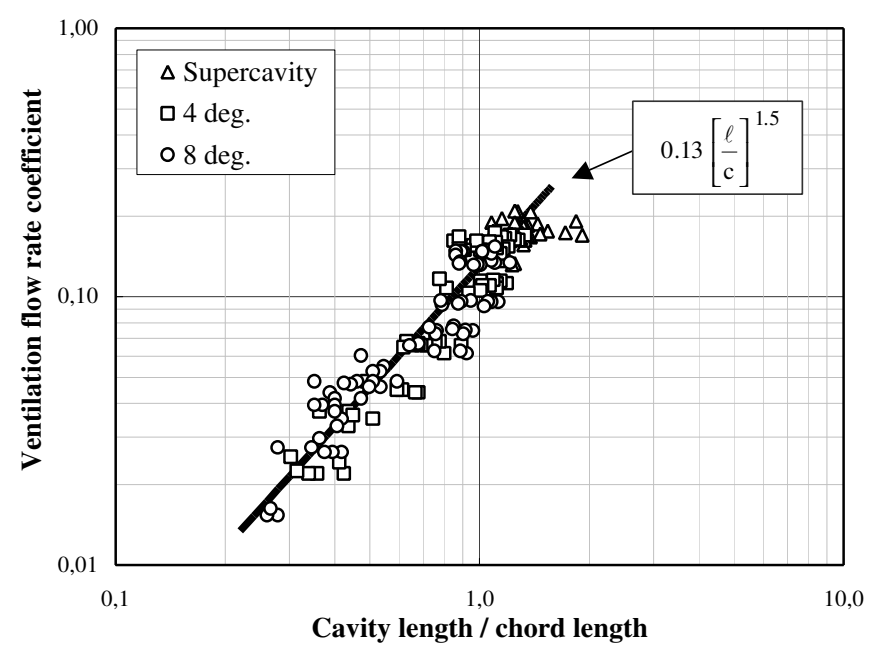

Figure 11: Evolution of the flow rate coefficient with the cavity length for a foil named EN foil (data adapted from Kamono et al. [13]). The flow rate coefficient was made non dimensional using the foil thickness.

\section{SCALING RULES WITH THERMODYNAMIC EFFECT}

The present results are based upon the assumption that cavitating flows are similar provided the cavitation number $\sigma_{\mathrm{c}}$ based on the real cavity pressure is constant, whatever may be the thermal effects. This assumption is re-examined here, on the basis of the Rayleigh-Plesset equation.

The classical Rayleigh-Plesset equation in which, for simplicity, the effects of surface tension, viscosity and non condensable gases are not considered, writes:

$$
\rho_{\ell}\left[\mathrm{R} \ddot{\mathrm{R}}+\frac{3}{2} \dot{\mathrm{R}}^{2}\right]=\mathrm{p}_{\mathrm{v}}\left(\mathrm{T}_{\mathrm{c}}\right)-\mathrm{p}
$$

$\mathrm{R}$ is the bubble radius and $\mathrm{p}$ is the time dependent pressure applied to the bubble. Introducing the temperature difference $\Delta \mathrm{T}=\mathrm{T}_{\infty}-\mathrm{T}_{\mathrm{c}}$, this can be written:

$$
\rho_{\ell}\left[\mathrm{R} \ddot{\mathrm{R}}+\frac{3}{2} \dot{\mathrm{R}}^{2}\right]+\frac{\mathrm{dp}_{\mathrm{v}}}{\mathrm{dT}} \Delta \mathrm{T}=\mathrm{p}_{\mathrm{v}}\left(\mathrm{T}_{\infty}\right)-\mathrm{p}
$$

The second term on the left hand side accounts for the thermodynamic effect. The determination of the temperature depression requires the solution of the heat equation in the liquid. For a mainly dimensional analysis, a simplified approach can be used to approximate this term (see e.g. Brennen [7]). It consists in assuming that the thermal boundary layer around the 
bubble has the typical thickness $\sqrt{\text { at }}$ after time $t$, so that the heat flux on the bubble wall can be approximated by:

$$
\mathrm{q}=\lambda \frac{\Delta \mathrm{T}}{\sqrt{\mathrm{at}}}
$$

If conduction only is involved, $\lambda$ is the usual thermal conductivity. As mentioned in the introduction, if heat transfer is enhanced by turbulence, the corresponding thermal diffusivity a has to be considered as an eddy thermal diffusivity (Kato [4]). Within this approximation, the heat balance for the bubble writes:

$$
q\left[4 \pi R^{2}\right]=\rho_{v} L \frac{d}{d t}\left[\frac{4}{3} \pi R^{3}\right]
$$

Combination of equations 26 and 27 gives the order of magnitude of the thermodynamic effect for the bubble:

$$
\Delta \mathrm{T} \approx \frac{\dot{\mathrm{R}} \sqrt{\mathrm{t}}}{\sqrt{\mathrm{a}}} \frac{\rho_{\mathrm{v}} \mathrm{L}}{\rho_{\ell} \mathrm{c}_{\mathrm{p} \ell}}
$$

The introduction of the previous estimate of the temperature depression into the Rayleigh-Plesset equation gives (cf. Brennen [7]):

$$
\left[\mathrm{R} \ddot{\mathrm{R}}+\frac{3}{2} \dot{\mathrm{R}}^{2}\right]+\Sigma \dot{\mathrm{R}} \sqrt{\mathrm{t}}=\frac{\mathrm{p}_{\mathrm{v}}\left(\mathrm{T}_{\infty}\right)-\mathrm{p}}{\rho_{\ell}}
$$

where $\Sigma$ is the parameter defined by:

$$
\rho_{\ell} \sqrt{\mathrm{a}} \Sigma=\frac{\rho_{\mathrm{v}} \mathrm{L}}{\rho_{\ell} \mathrm{c}_{\mathrm{p} \ell}} \frac{\mathrm{dp}_{\mathrm{v}}}{\mathrm{dT}}
$$

A very similar parameter was defined by Kato [4]. If this approach is not limited to the case of pure conduction but generalized to turbulent heat transfer, the $\Sigma$ parameter depends no longer on the only fluid temperature but also on the fluid flow itself and its turbulence. In order to exhibit scaling rules, the time dependence is replaced by a space dependence using $\mathrm{x}=\mathrm{Vt}$ where $\mathrm{x}$ is the distance along the streamline followed by the bubble. Eq. 29 is made non-dimensional using a characteristic diameter $\mathrm{D}$ of the inducer and a characteristic velocity $\mathrm{V}$. The following equation is obtained:

$$
\left[\overline{\mathrm{R}} \ddot{\overline{\mathrm{R}}}+\frac{3}{2} \dot{\overline{\mathrm{R}}}^{2}\right]+\Sigma \sqrt{\frac{\mathrm{D}}{\mathrm{V}^{3}}} \dot{\overline{\mathrm{R}}} \sqrt{\overline{\mathrm{s}}}=-\frac{\mathrm{C}_{\mathrm{p}}+\sigma}{2}
$$

In this equation, the derivatives are no longer time derivatives but derivatives with respect to the non dimensioned distance $\bar{x}=x / D \cdot \bar{R}$ is the non dimensioned bubble radius $\mathrm{R} / \mathrm{D}$ and $\mathrm{C}_{\mathrm{p}}$ the usual pressure coefficient. $\sigma$ is the cavitation number defined by equation 11 . For two geometrically similar flows characterized then by the same pressure distribution $C_{p}$, the solution $\overline{\mathrm{R}}(\overline{\mathrm{x}})$ is the same provided two scaling rules are satisfied.

As usually assumed for cavitating flows without thermal effects, the classical scaling rule on the cavitation number $\sigma$ must first be fulfilled. In addition, the similarity of the thermal effects requires an additional scaling law. This consists in the conservation of the non dimensioned parameter $\Sigma \sqrt{\mathrm{D} / \mathrm{V}^{3}}$. This law must be used to ensure the scaling of two cavitating flows with thermodynamic effect. For example, if a different fluid is used to simulate the real fluid flow (e.g. a refrigerant instead of liquid hydrogen), it indicates how to change the length scale or the velocity so that both flows remain similar. Now, if one flow is without thermodynamic effect $(\Sigma=0)$ as it is the case for cold water, the solution of equation 31 is obviously different of that with thermodynamic effect. There cannot be then a perfect scaling between two cavitating flows, with and without thermal effects. The differences in the solutions $\overline{\mathrm{R}}(\overline{\mathrm{x}})$ mean that the bubbles do not present geometrically similar developments along the blades. If generalized to the case of attached cavities, it can be expected that the cavities are not geometrically similar which may result in differences in their relative thickness for instance. In a recent numerical work, Tani \& Nagashima [15] have shown that the cavitation zone in liquid nitrogen is thicker than that in water. They observe that this might have consequences on cavitation instabilities and blockage. Strictly speaking, there is no complete scaling possible between two cavitating flows, with and without thermal effects. This is mainly due to the variations in temperature inside the cavity along the blade which induces variations in vapor pressure. The free streamline is then no longer at constant pressure as it is the case without thermodynamic effect. It is difficult to quantify the deviation which can be expected and, for limited thermodynamic effects, it can be conjectured that the classical scaling law on $\sigma_{\mathrm{c}}$ leads to a reasonable scaling of the flows. This was the assumption used in the present work.

\section{CONCLUSION}

The present paper reports the results of tests on a cavitating inducer conducted in refrigerant 114. This fluid was chosen to simulate the thermodynamic effect encountered in liquid hydrogen. The comparison of results in R114 and in cold water (i.e. without thermal effects) shows that, at a constant cavitation number, the leading edge cavities are less developed in the case of R114 than in the case of water. Moreover, an increase of the liquid temperature leads to shorter cavities, as it can be expected from the theory on thermodynamic effect.

From the consideration of the Rayleigh-Plesset equation, it is shown that the scaling of cavitation development between two geometrically similar flows requires two scaling laws to be satisfied. The first one is the classical conservation of the cavitation number $\sigma$ based on a reference pressure at infinity. The second one is relative to thermal effects and requires the conservation of an additional non-dimensional parameter $\Sigma \sqrt{\mathrm{D} / \mathrm{V} 3}$ where $\Sigma$ is a thermodynamic parameter classically introduced in most analysis of thermal effects (see eq.30) and D and $\mathrm{V}$ characteristic scales of length and velocity. Hence, there is no exact scaling possible between tests in cold water and in a thermosensible fluid as R114. Deviations in the geometries of the cavities are expected due to temperature changes along the cavity. The comparison of tests in R114 and in cold water is then not so simple. However, assuming that thermal effects are not too important, the cavity pressure can be considered as approximately constant and both flows can be considered as almost similar provided the cavitation number $\sigma_{c}$ based on the actual cavity pressure is kept constant. This scaling law is used here to compare tests in water and R114.

To observe the same development of cavitation in R114 than in cold water, it is necessary to lower the cavitation number. Using the scaling law on $\sigma_{\mathrm{c}}$, it is then possible to estimate the temperature depression inside the cavity from this measured shift in cavitation number. The results are presented in terms of the B- 
factor of Stepanoff. It is shown that the B-factor does not depend significantly on the fluid temperature neither on the rotation speed of the inducer in the present domain of investigation. It depends mainly upon the degree of development of the cavitation and is nearly proportional to the cavity length. These trends are consistent with the entrainment theory in which basic assumptions are made concerning the convection heat transfer coefficient and the flow-rate of vapor entrained at the rear of the cavity.

During the tests, the development of cavitation instabilities is also detected from the analysis of pressure fluctuations. On the present inducer, it is observed that alternate blade cavitation starts for a critical development of the leading edge cavities characterized by a length (measured along the mean radius between hub and casing) of about $25 \%$ of blade spacing. The onset of alternate blade cavitation is affected by a thermal delay given by a value of the B-factor of the order of 2 . On the other hand, the transition from alternate blade cavitation to rotating cavitation could not be correlated to a critical development of sheet cavities so that it is supposed that tip-leakage cavitation also plays an important role in the onset of rotating cavitation.

Present estimates of the temperature depression are deduced from visualizations and basic scaling laws. The only way to validate the approach would be to measure directly the temperature or the pressure inside the cavities which develop on the rotating blades.

\section{ACKNOWLEDGMENTS}

We would like to thank our colleagues R. Brillault, E. Janson and M. Riondet for providing support in the preparation and running of tests. We would also like to acknowledge the contribution of P. Morel (SNECMA) in the initiation of the present research. Useful discussions, suggestions and information were provided by several colleagues, especially D.H. Fruman and Y. Lecoffre, in the framework of the COSCAV meeting. This research was partly supported by CNES.

\section{REFERENCES}

[1] Stahl H.A., Stepanoff A.J. \& Phillipsburg N.J. "Thermodynamic aspects of cavitation in centrifugal pumps" ASME J. of Basic Eng., 1956, 1691-1693.

[2] Stepanoff A.J. "Cavitation properties of liquids" J. of Eng. for Power, April 1964, 195-200.
[3] Holl J.W., Billet M.L. \& Weir D.S. "Thermodynamic effects on developed cavitation" J. of Fluids Eng., Dec.1975, 507-514.

[4] Kato H. "Thermodynamic effect on incipient and developed sheet cavitation" Int. Symp. on Cavitation inception, FED-Vol.16, New-Orleans (USA), Dec. 9-14, 1984, 127-136

[5] Fruman D.H., Reboud J.L. \& Stutz B. "Estimation of thermal effects in cavitation of thermosensible liquids" Int. J. of Heat and Mass Transfer, Vol.42, 1999, 3195-3204.

[6] Fruman D.H., Benmansour I. \& Sery R. "Estimation of the thermal effects on cavitation of cryogenic liquids" Cavitation and Multiphase Flow Forum, ASME FED 109, 1991, 93-96.

[7] Brennen C.E. "Cavitation and Bubble Dynamics" Oxford Univ. Press 1995.

[8] Hord J. "Cavitation in liquid cryogens" NASA reports CR2054, CR-2156 (1972), CR-2242 (1973), CR-2448 (1974).

[9] Billet M.L. "Thermodynamic effects on developed cavitation in water and Freon 113" Master of Science Thesis, The Pennsylvania State University, March 1970.

[10] Franc J.P., Janson E., Morel P., Rebattet C. \& Riondet M. "Visualizations of Leading Edge Cavitation in an Inducer at Different Temperatures" $4^{\text {th }}$ Int. Symp. on Cavitation, Pasadena (USA), June 20-23, 2001.

[11] Billet M.L., Holl J.W. \& Weir D.S. "Correlations of Thermodynamic Effects for Developed Cavitation" J. of Fluids Eng., Vol.103, Dec.1981, 534-542

[12] Tsujimoto Y. "Simple rules for cavitation instabilities in turbomachinery" $4^{\text {th }}$ Int. Symp. on Cavitation, Pasadena (USA), June 20-23, 2001.

[13] Kamono H., Kato H., Yamaguchi H. \& Miyanaga M. "Simulation of cavity flow by ventilated cavitation on a foil section" FED-Vol.153, Cavitation and Multiphase Flow, ASME 1993, 183-189.

[14] Holman J.P. "Heat transfer" 1997 McGraw-Hill.

[15] Tani N. \& Nagashima T. "Numerical analysis of cryogenic cavitating flow on hydrofoil - Comparison between water and cryogenic fluids" $4^{\text {th }}$ Int. Conf. on Launcher Technology, Dec. 3-6, 2002, Liege (Belgium). 